\title{
Public Funds and Entrepreneurship: A Cognitive Economics Approach
}

\author{
KOUAKOU Thiédjé Gaudens-Omer \\ Economics Department \\ Alassane Ouattara Bouaké University \\ Ivory Coast
}

\begin{abstract}
This paper studies the effectiveness of public policies for the financing of entrepreneurship in developing countries. The approach of the cognitive economics makes it possible to resort to psychological matters in this analysis. Through an informed principal model in the form of Perfect Bayesian game, we show that when potential creators are less informed about their project and lack the capacity for self-determination, the public funds could induce an eviction of their intrinsic motivation. The consequences are various: strong failure rate of business projects, diversion of public funds to other projects, etc. The public authorities can reinforce the effectiveness of public funds by taking into account cognitive behavior of the potential creators and by improving their access to information.
\end{abstract}

Keywords: entrepreneurship, contract theory, cognitive economics, intrinsic and extrinsic motivations, Perfect Bayesian game.

JEL classification: D82, D24, L26

\section{Introduction}

Financing entrepreneurship is a major issue for growth and development in all countries. The main lever of entrepreneurial finance is the private finance that is differentiated according to the life cycle of the firm (Pfeffer and Salancik 1978, Castrogiovanni 1991). While private equity covers almost the entire development process of the company, bank financing is important in the development and maturity phases. In the early stages of business development, venture capital financing and informal family finance (family finance), friends and business angels predominate. This last form of proximity financing seems to be particularly crucial to the emergence of opportunity entrepreneurship and the development of entrepreneurial activities with high growth potential. In the creation phase of the company, self-financing is the main source of private financing. Almost everywhere, private financing is insufficient to finance start-ups, hence the use of public financing (Bissiriou, 2011). The latter, playing an active role in financing the early stages of the creation of innovative start-ups, has two components: the indirect route of tax breaks (research tax credit, risk capital, etc.) and the direct way of grants or repayable advances (co-financing of bank credits, guarantee of bank loans, quasi-equity, etc.). In these forms, public financing is an incentive to promote entrepreneurship and economic growth. In developing countries (DCs), public financing is becoming more important as private financing is becoming scarce. This public financing of entrepreneurship is largely aimed at promoting self-employment and integration through economic activity, in a context of persistent unemployment.

Public funds appear here as a form of incentive that influences the choice of the potential entrepreneur as to his decision to undertake. In other words, public financing has an impact on the entrepreneurial offer, which is nothing more than the decision for a potential creator, to become an entrepreneur or not. In developing countries, many business creation projects supported by public funds have, on the contrary, led to various abuses: the laxity that leads to the failure or abandonment of the project, the misappropriation of funds to projects other than entrepreneurship. The proliferation of such incidents has challenged the effectiveness of public policies promoting entrepreneurship in developing countries. Studies dealing with the causes of these failures highlight various factors: social barriers to entrepreneurship that thwart the requirements of entrepreneurial rationality (Alby, Auriol and Nguimkeu, 2013), insufficient managerial capacity of young entrepreneurs (Sohot, 2016), etc. Hence the proposal to rethink the ideology of the functioning of these funds taking into account the cultural roots of the beneficiaries. 
In this paper, we highlight another cause of the inefficiency of some public funds promoting entrepreneurship in developing countries: the decline in intrinsic entrepreneurial motivation linked to the granting of these funds. The notion of intrinsic motivation to undertake refers to that of intention to undertake, which can be defined as the individual will to create, emerging from a cognitive process conditioned by the socio-cultural, political and economic context. This notion proves the explanatory depth of the psychological predispositions in the field of business creation (Saporta and Verstraete, 2006). Thus, our analysis of the impact of public financing as an incentive factor for the entrepreneurial offer shares with Baumol (1968) the idea that much of the entrepreneurial logic is played out within the consciousnesses and cognitions of individuals. This is attested by the flourishing of the psychological theory of entrepreneurship. But our reflection does not share the idea of Baumol (op.cit.) that economic theory is less competent to study the determinants of the supply of entrepreneurship that is more sociology and psychology.

This belief leads Baumol not to study the factors that influence the entrepreneurial supply. He therefore considers the entrepreneurial offer as given and is content to analyze the optimal allocation of constant entrepreneurial talents towards the most productive jobs for society. Thus, Baumol (1990) shows the need for correct incentives to promote productive entrepreneurship. Indeed, according to him, entrepreneurship, productive in some societies, can be unproductive, even destructive in others. It can induce a decline in income and social well-being, especially when the entrepreneur earns money to the detriment of others. Such incentives play a crucial role in reconciling the personal interests of entrepreneurs with the collective interest. Such productive entrepreneurship combines inputs in a profitable way to explain much of the economic growth (Elliasson and Henrekson, 2004). In a nutshell, according to Baumol, the real problem is not so much to increase the number of entrepreneurs in a country as to optimally allocate, through correct incentives, constant entrepreneurial talents towards the most productive uses for the society. We concede to Baumol the fact that many works that have studied the determinants of the entrepreneurial offer have failed to integrate the psychological dimension that pushes from intention to the act of doing business. These works, considering the entrepreneurial offer as not constant (Lucas, 1978; Kihlstrom and Laffont, 1979; Holmes and Schmitz, 1990; Casson, 1982) identifies as determinants of this offer: wealth, the risk of unemployment and the duration employment in the salaried sector (Eisenhauer, 1995), the social rights of wage labor (Papillon, 2000), the socio-professional career (Douglas, Sheperd and Lévesque, 2002). Other factors that influence the decision of a potential creator to become an entrepreneur or not are the sunk costs in the formal sector (Djankov et al., 2002; Auriol and Warlters, 2005), the degree of imperfections in financial markets (Straub, 2005; De Mel et al., 2008; Grimm, Krueger and Lay, 2011), credit rationing and financial constraints (Stiglitz and Weiss, 1981; Meza and Webb, 1987; Evans and Jovanovic, 1989), etc.

Our study is based on the growth of cross-fertilization between economics and psychology observed in recent years (Bénabou and Tirole, 2003; Tirole 2009; DellaVigna, 2009; Ariely, Bracha and Meier, 2009). In doing so, it enriches the understanding of the determinants of the entrepreneurial offer, by psychological considerations. This analysis, which explains the relative inefficiency of public funding policies for young entrepreneurs by an eviction of their intrinsic entrepreneurial motivation, resorts to the cognitive economics approach of Benabou and Tirole (2003) and Tirole (2009). These are based on a model of informed principal, and show that when the intrinsic motivation of the agent is not well defined in general because endogenous nature, intrinsic motivation and extrinsic motivation can interact: give extrinsic incentives can decrease and even oust intrinsic motivation. In other words, this model highlights different facets of the identity of individuals. This is not unique and invariant (Bessis et al., 2006). If people are provided with a reflexive capacity, it is possible that they modify the balance of their motivations under the effect of new economic policy measures. They are led to re-arrange these two types of motivation to make their decisions. Individuals can activate extrinsic motivations and reject intrinsic motivations in the background. The rest of our paper is organized as follows: in Section 2, we analyze the interactions between public funds and the intrinsic motivation of the potential entrepreneur and the optimal level of public funds in a context of symmetrical information and asymmetrical information. Section 3 discusses the effectiveness of entrepreneurship financing policies. Section 3 concludes our study.

\section{Public Fund and Entrepreneurial Offer: a theoretical Model}

\subsection{The assumptions of the model}

We consider a developing economy characterized by endemic youth unemployment. With an interest in reducing unemployment, for example for electoral or other reasons, the State is implementing a policy to promote youth entrepreneurship through public subsidies. 
It is assumed that unemployed youths selected as potential entrepreneurs make a necessity entrepreneurship, not an opportunity entrepreneurship. We use the framework of a principal-agent model where the principal is the State and the agent, a potential young entrepreneur. The latter has the choice between starting a business and becoming a worker-employee without a business. When he creates the enterprise, the agent has a probability of success of $\theta$ and he obtains a psychological gain $U$. In case of failure, with probability $1-\theta$, this psychological gain is zero. In addition, it is assumed that the agent suffers an opportunity $\operatorname{cost} C$ corresponding to the psychological gain that the salaried work, an external opportunity, would have procured for him. In this context, the expected utility of the potential creator, when undertaking, is: $\theta U-C$. Its expected utility is normalized to 0 when it does not start a business. Thus, the agent will create the company if it finds it attractive enough, that is to say, if its success gives him a significant gain at a low cost.

The principal wins $S$ if the agent undertakes and succeeds, and 0 if the agent does not start. Its expected utility is therefore: $\theta S+(1-\theta) .0=\theta S$. The state, the principal, would like the agent to take the initiative. Consider a very simple two-period game. In the first period, the state assumed to be risk-neutral, has information on the probability of success of the enterprise project $\theta$; he chooses to incite the agent to undertake by granting him a public fund $F$. In this case, his expected utility is $\theta[S(F)-F]$ with $S^{\prime}()>$.0 and $S^{\prime \prime}()<$.0 . The state has an informational advantage over $\theta$. It is assumed that the agent does not know this parameter $\theta$. Such an assumption may seem surprising. But in developing countries, it is common to see, because of a weak local entrepreneurial culture, potential entrepreneurs who are poorly informed about their project (Emran and Stiglitz, 2007). It is also assumed that in developing countries, the weak local entrepreneurial culture has another consequence: the potential creator attributes the success of his project to the external conditions of the environment rather than to his own entrepreneurial abilities. In other words, he shows fatalism and lack of self-determination. In the second period, the agent infers this parameter by receiving a signal that he tries to interpret. He then chooses to undertake or not. The concept of equilibrium sought will then be that of a perfect Bayesian equilibrium. We are in the framework of a model of the principal informed.

In this model, the expression of the expected utility of the agent, $\theta U-C$, is its net motivation to undertake in the absence of any public funds. It can be defined as his intention to undertake. This concept, derived from psychology and management, has different names according to the authors: conviction in some (Davidson, 1995), desirability in others (Emin, 2003). For the former, the conviction is that feeling, more or less strong, that business creation is an activity within reach, that he would be happy to practice it, that it would solve his personal and financial problems. For the latter, desirability is defined as the attractiveness of creating a business for the potential creator. The intention to undertake here corresponds to the intrinsic motivation of the agent. Public funding will be taken here as his extrinsic motivation. In doing so, it becomes possible to reinterpret the study of the impact of public funding on the entrepreneurial offer in terms of interactions between extrinsic motivation and intrinsic motivation. Such an analysis is all the more relevant since studies have shown that when the intrinsic motivation of the agent is not well defined in general because of an endogenous nature, intrinsic motivation and extrinsic motivation can interact: giving extrinsic incentives can decrease and even eliminate intrinsic motivation (Benabou and Tirole, 2003). What about the field of entrepreneurship? We distinguish two situations: in the first case, we suppose that the parameter $\theta$, the probability of success of the project is common knowledge of the State and the potential entrepreneur; in the second case, we return to our assumption of an informational advantage of the State on $\theta$.

\subsection{Interaction between intrinsic motivation and extrinsic motivation with symmetric information}

In symmetric information, the parameter $\theta$ is a common knowledge of the public authorities and the potential creator. The public authorities promise an amount $(F)$, contingent on the passage to the act of doing business. In this case, the expected utility of the potential creator becomes: $\theta(U+F)-C$. It passes to the act of undertaking if this expected utility is positive. The participation constraint of the potential creator is therefore $\theta(U+F)-$ $C \geq 0$. It is rewritten as follows:

$$
\underbrace{[\theta U-C]}_{\begin{array}{c}
\text { intrinsic } \\
\text { motivation }
\end{array}}+\underbrace{\theta F}_{\begin{array}{c}
\text { extrinsic } \\
\text { motivation }
\end{array}} \geq 0
$$

This participation constraint shows three interesting results: 
- Starting from a situation where the potential creator does not intend to undertake: $\theta U-C<0$, there is a level of public funds $F$ that pushes him to the act of doing business.

- The expression $\theta U-C$ does not formally depend on $F$. There is no interaction between public financing and the intrinsic motivation to undertake. Extrinsic motivation makes it possible to incite him to act, thus influencing the entrepreneurial offer, without interacting with intrinsic motivation.

- Thus, since the intrinsic motivation remains stable, an increase in public funding leads to the participation constraint being respected: there is then an increase in the entrepreneurial supply.

At present, let us characterize the first best optimal public financing that the State proposes to the potential entrepreneur. When the government gives financial incentives, his utility becomes $S(F)-F$ if case of success of the entrepreneurial project (with probability $\theta$ ). In case of failure, $S(F)=0$ so that the utility of the State is $-F$. His expected utility is $\theta[S(F)-F]+(1-\theta)(-F)=\theta S(F)-F$. The resolution of the government program is to maximize his objective-function $\max _{F} \theta S(F)-F$ under the participation constraint of the potential entrepreneur:

$$
\begin{gathered}
\operatorname{Max}_{F} \theta S(F)-F \\
\text { s.t }[\theta U-C]+\theta F \geq 0
\end{gathered}
$$

Since public funds are expensive for the state, the state chooses the optimal level of public funds so as to saturate the participation constraint of the agent. First-order conditions give the first best optimal level of public funds:

$$
\left\{\begin{array}{l}
F^{F B}=S^{\prime-1}(1 / \theta) \\
F^{F B}=C / \theta-U
\end{array}\right.
$$

Proposition 1: In symmetric information, there is a clear separation between the intrinsic motivation to undertake and public financing. In other words, the intention to undertake does not interact with the financial incentive of the State. In this case, the entrepreneurial supply grows with public funds. The first best optimal public funds offer is $F^{F B}=C / \theta-U$.

\subsection{Interaction between intrinsic motivation and extrinsic motivation with asymmetric information}

The state has an informational advantage over the probability of success of the project, $\theta$. Observing the offer of public financing, the potential creator draws an interpretation on the level of $\theta$ that he does not observe. Everything happens as if the State sends a signal to the potential creator when announcing public funding $F$. The latter perceives this announcement as a signal on the risk of the project. It infers that the reason the state must intervene to ensure that the constraint of participation is satisfied is that the project must have a low probability of success. This is the agent's interpretation of the observation of the imprecise signal $\sigma$ on the level of $\theta$. In other words, he considers public funding announced by the State as bad news on the probability of success of the project. He inevitably accepts this verdict related to economic conditions without acting on his own to influence the probability of success of his project.

The perception of $\theta$ by the agent is the expectation of $\theta$ given the information that he owns $(\sigma)$ plus the information sent to him by the public authorities through the choice of $F$. Formally, this perception is written: $E(\theta / \sigma, F)$. The potential entrepreneur will only act if his own information $\sigma$ exceeds a threshold $\sigma^{*}$ which depends on $F: \sigma \geq \sigma^{*}(F)$. Finally, the perception of $\theta$ by the agent has a Bayesian form: $E\left(\theta / \sigma^{*}(F), F\right)$. Thus, he will only create the business if:

$$
\left[E\left(\theta / \sigma^{*}(F), F\right) U-C\right]+E\left(\theta / \sigma^{*}(F), F\right) F \geq 0
$$

Where $\left[E\left(\theta / \sigma^{*}(F), F\right) U-C\right]$ : intrinsic motivation to undertake; $F$ : public funds offer.

This participation constraint calls for some comments:

- Starting from a situation where the potential creator has no intention of undertaking: $E\left(\theta / \sigma^{*}(F), F\right) U-C<$ 0 , there is a level of public fund $F$ that pushes him to the act of undertaking.

- The expression $E\left(\theta / \sigma^{*}(F), F\right) U-C$ formally depends on $F$. There is now an interaction between public financing and the intrinsic motivation to undertake. Extrinsic motivation makes it possible to incite the agent to act, thus influencing the entrepreneurial offer, while interacting with intrinsic motivation.

- Thus, since the intrinsic motivation is no longer stable, an increase in public funding does not systematically lead to an increase in the entrepreneurial supply. 
Indeed, starting from the relation $\left[E\left(\theta / \sigma^{*}(F), F\right) U-C\right]+E\left(\theta / \sigma^{*}(F), F\right) F \geq 0$, if the public authorities increase the supply of public funds $(F)$, the potential entrepreneur infers from this rise bad news about the likelihood of success of the project. The perception of this probability, $E\left(\theta / \sigma^{*}(F), F\right)$, decrease. Ultimately, the increase in extrinsic motivation induces a decrease in intrinsic motivation $\left[E\left(\theta / \sigma^{*}(F), F\right) U-C\right]$. There is an eviction of intrinsic motivation by extrinsic motivation.

To determine the second best optimal level of public funds, one maximizes the function-objective $\max _{F} \theta S(F)-$ $F$ under the participation constraint of the potential entrepreneur:

$$
\begin{gathered}
\operatorname{Max}_{F} \theta S(F)-F \\
\text { s.t }\left[E\left(\theta / \sigma^{*}(F), F\right) U-C\right]+E\left(\theta / \sigma^{*}(F), F\right) F \geq 0
\end{gathered}
$$

The first-order conditions give the second best optimal level of public funds:

$$
\left\{\begin{array}{c}
F^{S B}=S^{\prime-1}(1 / \theta) \\
F^{S B}=C / E\left(\theta / \sigma^{*}(F), F\right)-U
\end{array}\right.
$$

By comparing the first best optimal level of public funds and the second best optimal level, it is shown that $F^{S B}>F^{F B}$ (proof in appendix A1). To understand this result, let's start from the situation where the public authorities announce the first best optimal level, the amount of public funds in asymmetric information. The potential creator, less informed, does not observe $\theta$. He does not know that this amount is compatible with a probability of success $\theta$. He interprets the level of public funds as bad news about the probability of success of the project. Its intrinsic motivation is therefore reduced in such a way that the State must increase the optimal level of public funds of $F^{F B}$ at $F^{S B}$, in order to ensure that the participation constraint of the potential creator is satisfied.

Proposition 2: In asymmetric information, there is no longer any separation between the intrinsic motivation to undertake and the public financing. The intrinsic motivation of the potential creator, interacting with the financial incentive of the state, is no longer stable. Under the effect of public funding, the agent re-organizes his motivations by activating extrinsic motivation and gradually rejecting his intrinsic motivation. The second best optimal level of public funds is $F^{S B}=C / E\left(\theta / \sigma^{*}(F), F\right)-U$. This level is higher than the first best one: $F^{S B}>F^{F B}$.

This result shows the endogenous character of the intrinsic motivation to undertake. It is consistent with the idea of scalability of entrepreneurial intent in the psychological theory of entrepreneurship (Krueger and Carsrud 1993, Krueger and Brazeal 1994). The possibility for the potential entrepreneur to activate extrinsic motivations and to reject the intrinsic motivations in the background is also consistent with the identification of different facets of the identity of individuals in Bessis and al (2006). Moreover, this result validates theoretically, for the field of entrepreneurship, the general result of Benabou and Tirole (2003) according to which when the intrinsic motivation of the agent is not well defined in general, the intrinsic motivation and the extrinsic motivation can interact: giving extrinsic incentives can decrease and even crowd out intrinsic motivation.

\section{Public Policy Recommendations}

The optimal offer of public funds (first best, second best) that we have determined is compatible with the entrepreneurial act of the potential creator. The effect of evicting intrinsic motivation by extrinsic motivation does not prevent the creator from acting out. Let's try to see what happens out of optimal equilibrium, in a situation where the potential creator may not act out. Such an analysis makes it possible to study the influence of the crowding out effect on the entrepreneurial supply. This will allow us to deduce consequences for the effectiveness of public policies to promote entrepreneurship.

To do this, define $\hat{F}^{I A}$ the amount of public funding that makes the potential creator indifferent between creating and not creating, in asymmetric information ${ }^{1}: G\left(\hat{F}^{I A}\right)=0 \Rightarrow \hat{F}^{I A}=C-\left[E\left(\theta / \sigma^{*}(F), F\right) U\right]$. In the same way, we let $\hat{F}^{I S}$ : threshold amount of public financing in symmetric information.

If in asymmetric information, the amount of public funding is in the range $\left[\hat{F}^{I S}, \hat{F}^{I A}\right]$, the crowding out effect reduces the intrinsic motivation to the point where the potential creator has not interest in acting out.

${ }^{1}$ We introduce the function $G: F \mapsto G(F)=\left[E\left(\theta / \sigma^{*}(F), F\right) U-C\right]+E\left(\theta / \sigma^{*}(F), F\right) F$. 
Thus, over this interval, the asymmetric information entrepreneurial offer decreases with the crowding out effect (proof in appendix A2). Such a situation can lead to excesses: the potential creator can accept the public funds without ever taking the act of doing business. Driven more by the public funds of the State than by a real intrinsic motivation, he can disappear in the nature with the public funds, in the course of realization of the project.

When the amount of public funding is in the range $\left[\hat{F}^{I A}, \infty\right]$, the crowding out effect reduces the intrinsic motivation of the potential creator without preventing it from undertaking (proof in appendix A2). The entrepreneurial supply is therefore increasing over this interval. However, the agent undertakes without much intrinsic motivation. This induces a very strong propensity to fail in his business because entrepreneurial success is a matter of strong internal motivation.

These two previous situations can explain the ineffectiveness, in developing countries, of certain public funds allocated to the promotion of entrepreneurship. In Côte d'Ivoire, for example, several project promoters who received public funding called social funds either suffered bitter failures or disappeared with the funds obtained. Our model explains this inefficiency by not taking into account the cognitive behavior of the project leaders. We have seen that such drifts do not appear in case of symmetrical information because the intrinsic motivation of the agent is never altered by the granting of public funds. In addition, the optimal level of public funds is lower, therefore less expensive for the community, than in asymmetric information situation. In order to be effective, entrepreneurship promotion policies must take into account the cognitive behavior of potential creators and their access to information. The better they will be informed about their project through support and training in the various topics of business creation: business plan, market study, etc., the more their intrinsic motivation to undertake will be stable, without risk of alteration and crowding-out by financial incentives.

\section{Concluding Remarks}

Our theoretical model shows that the effectiveness of public policies promoting entrepreneurship in developing countries may depend on the cognitive behavior of potential creators. When the latter are poorly informed about their project and have little capacity for self-determination, public funds can change the balance of their motivations. They are likely to activate their extrinsic motivation and reject in the background their intrinsic motivation. What ultimately motivates them to undertake is, in this case, less their intrinsic motivation to undertake than the financial assistance of the State. Some abuses can result from this, such as laxity that leads to the failure of the project or even the abandonment of the project and the misappropriation of public funds for other projects other than entrepreneurship. These drifts are contained and minimized when the public authorities improve access to information for potential creators. This enhances the effectiveness of public funds earmarked for business creation. Our results validate theoretically, for the field of entrepreneurship, the general result of Benabou and Tirole (2003) according to which extrinsic motivation can evict the intrinsic motivation of the agent. This cognitive economics approach contributes to enriching the economic theory of entrepreneurship with psychological considerations. In doing so, it takes the opposite of Baumol (1968) for whom economic theory is less competent to study the entrepreneurial supply that comes under the analysis of psychology.

This study can be expanded in several directions. First, theoretically, our model can be enriched by the modification of certain hypotheses: our model admits linearity between intrinsic motivation and extrinsic motivation. We can study the case of non-linearity. For example, by making the agent's objective function depend on its expected profit, which itself depends on the level of capital, the public fund increases this level of capital (repayable advances: co-financing of bank loans, guarantee of bank loans, quasi-equity). Does this affect or not the independence between intrinsic motivation and extrinsic motivation in symmetrical information situation? In this case, how do public funds affect intrinsic motivation? Moreover, at the empirical level, it is possible to verify two testable hypotheses that our model highlights: (1) the intrinsic motivation to undertake (intention to undertake) of uninformed potential creators decreases with the supply of public funds (tax relief, direct subsidies); (2) there is a public threshold below which the rate of diverted projects is high; beyond this public threshold, the failure rate of non-diverted projects is high. Further study is expected in the future.

\section{References}

Alby, P., Auriol, E., Nguimkeu, P. (2013), « Social barriers to entrepreneurship in Africa: the forced mutual help hypothesis », Working Paper, may 2013.

Ariely, D., Bracha, A.,Meier, S. (2009) "Doing Good or Doing Well? Image Motivation and Monetary Incentives in Behaving Prosocially," American Economic Review, 99(1): 544-55. 
Auriol, E., Warlters, M. (2005), « Taxation base in developing countries », Journal of Public economics, vol. 89(4), pp. 625-646.

Baumol, W. J. (1968): «Entrepreneurship in economic theory », American economic review, vol. 58, n², pp.6471.

Baumol, W.J. (1990), “ Entrepreneurship : productive, unproductive, and destructive », Journal of Political Economy 98(5) : 893-921.

Benabou, R., Tirole, J. (2003), « Intrinsic and extrinsic Motivation », Review of economic studies, 70, p. 489-520.

Bessis, F., Chaserant, C., Favereau, O., Thevenon, O. (2006), «L'identité sociale de l'homo conventionalis », in Economie des conventions, Méthodes et résultats, T.1, sous la direction de Eymard-Duvernay, F., la Découverte, Paris.

Bissiriou, G. (2011), «Les partenariats publics-privés dans le financement de l'entrepreneuriat », Bulletin de l'observatoire des politiques économiques en Europe, n²4, été 2011, pp 41-47.

Casson, M. (1982), "The entrepreneur: an economic theory », Oxford: Martin Robertson, $2^{\text {nd }}$ ed., Edward Elgar, 2003).

Castrogiovanni, G.J. (1991), «Environmental munificence: a theoretical assessment», The academy of management Review, vol. 16, $\mathrm{n}^{\circ} 3$ (july), pp. 542-565.

Davidson, P. (1995), «Determinants of entrepreneurial intentions", Communication au colloque «Rent IX Workshop », Piacenza, Italy, Nov.

Dellavigna, S. (2009) "Psychology and Economics: Evidence from the Field," Journal of Economic Literature, 47(2): 315-72.

De Mel, S., McKenzie, D., et Woodruff, C. (2008), "Returns to capital: results from a randomized experiment », The Quarterly Journal of Economics, vol. 123(4): 1329-1372.

De Meza, D., Webb, D.C. (1987), “Too much investment: a problem of asymmetric information », The Quarterly Journal of Economics, vol. 102 (2), pp. 281-292.

Djankov, S., La Porta, R., Lopez-de-Silanes, F., Shleifer, A. (2002), « The regulation of entry », The Quarterly Journal of Economics, vol. 117 (1), pp. 1-37.

Douglas, E.J., Lévesque, M. , Sheperd, D.A. (2002), «Employment or self-employment: a dynamic utilitymaximizing model », Journal of Business Venturing, vol. 17(3), pp. 189-210.

Eisenhauer, J.,G. (1995), «The entrepreneurial decision: economic theory and empirical evidence », Entrepreneurship Theory and Practice, Summer : 67-79.

Elliasson, G., Henrekson, M. (2004), «William J. Baumol: an entrepreneurial economist on the economics of entrepreneurship", Small Business Economics, vol. 23, August, pp. 1-7.

Emin, S. (2003), "L'intention de créer une entreprise des chercheurs publics : le cas français » Thèse de doctorat en Sciences de Gestion, Université Grenoble Pierre Mendès-France.

Emran, M.S., Stiglitz, J.E. (2007), "Financial liberalization, financial restraint, and entrepreneurial development », http://cid.harvard.edu/neudc07docs/neudc07_s5_p02_emran.pdf.

Evans, D., Jovanovic, B. (1989), «An estimated model of entrepreneurial choice under liquidity constraints", Journal of Political Economy, 97, pp. 808-827.

Grimm, M., Krueger, J., Lay, J. (2011), «Barriers to entry and returns to capital in informal activities: evidence from sub-saharian Africa », Review of Income and Wealth, vol. 57(1), May, pp. 27-53.

Hernandez, E.-M. (2006), "Les trois dimensions de la décision d'entreprendre", Revue française de gestion, $\mathrm{n}^{\circ} 168-169$, pp. 337-357.

Holmes, T., Schmitz, J. (1990), «A theory of entrepreneurship and its application to the study of business tranfers », Journal of Political Economy, vol. 98 (2), pp. 265-294.

Kihlstrom, R. E., Laffont, J.-J. (1979), «A general equilibrium entrepreneurial theory of firm formation based on risk aversion", Journal of Political Economy, vol. 87, n²4, pp. 719-748.

Krueger, N.F., Brazeal, D.V. (1994), "Entrepreneurial potential and potential entrepreneurs", Entrepreneurship Theory and Practice, 18(3), 91-104.

Krueger, N.F., Carsrud, M.D. (1993), “Entrepreneurial intentions: applying the theory of planned behavior", Entrepreneurship and regional development, 1993, vol. 5, pp. 315-330.

Lucas, R.E. (1978), "On the size distribution of business firms", The Bell Journal of Economics, vol.9, n², autumn, pp. 508-523. 
Papillon, J.-C. (2000), «Economie de l'entreprise. De l'entreprise à la gouvernance », Editions Management et société, Caen, $2^{\text {nd }}$ édition 2000.

Pfeffer, J., Salancik, G.R. (1978), "The external control of organizations: a resource dependance perspective”, Harper \& Row, New York.

Saporta, B., Verstraete, T. (2006), “ Création d'entreprise et Entrepreneuriat », Editions de l'ADREG, p. 517.

Sohot, R. D. (2016), "Les déterminants sociaux de la non émergence d'une catégorie d'entrepreneurs chez les bénéficiaires des fonds sociaux en Côte d'Ivoire », Thèse de doctorat en sociologie, Université Félix Houphouët-Boigny.

Stiglitz, J., Weiss, A. (1981), "Credit rationing in markets with imperfect information", American Economic Review 71: 393-410.

Straub, S. (2005), "Informal sector: the credit market channel", Journal of development Economics 78, 299-321.

Tirole, J. (2009), «Motivation intrinsèque, incitations et normes sociales », Revue économique, Volume 60, p. 577-589.

Van Stel, A., Storey, D. J., Thurik, R. A. (2007), "The effect of business regulations on nascent and young business entrepreneurship". Small Business Economics 28: 171-186.

\section{Appendix A1}

Let us show that $F^{S B}>F^{F B}$; we know that:

$$
\begin{gathered}
F^{S B}=C / E\left(\tilde{\theta} / \sigma^{*}(F), F\right)-U \\
F^{F B}=C / \theta^{*}-U \\
F^{S B}-F^{F B}=C / E\left(\tilde{\theta} / \sigma^{*}(F), F\right)-C / \theta^{*}
\end{gathered}
$$

So just compare $\theta^{*}$ and $E\left(\tilde{\theta} / \sigma^{*}(F), F\right)$

In symmetric information, we can write $\theta^{*}=\mathrm{E}\left(\theta^{*} / \sigma^{*}(F), F\right)$. We therefore try to compare $\mathrm{E}\left(\sigma^{*}(F), F\right)$ and $E\left(\tilde{\theta} / \sigma^{*}(F), F\right)$. Given that in asymmetric information, the potential creator uses the amount of $F$ as a signal to infer bad news about $\tilde{\theta}$, his perception of $\tilde{\theta}$ will be set at a lower level than in a symmetric information situation, from where :

$$
\theta^{*}=\mathrm{E}\left(\theta^{*} / \sigma^{*}(F), F\right)>E\left(\tilde{\theta} / \sigma^{*}(F), F\right)
$$

Consequently, $F^{S B}-F^{F B}>0 \Rightarrow F^{S B}>F^{F B} \quad$ QED

\section{Appendix A2}

Consider the function $G: F \mapsto G(F)=\left[E\left(\theta / \sigma^{*}(F), F\right) U-C\right]+F$. Let $\widehat{F}$ the amount of public fund that makes the potential creator indifferent between creating and not creating $\left(G\left(\hat{F}^{I A}\right)=0\right)$. We have:

$$
\hat{F}^{I A}=C-\left[E\left(\theta / \sigma^{*}(F), F\right) U\right]
$$

For $F>\hat{F}^{I A} \Rightarrow G(F)>0$ : the potential creator goes on to create despite the eviction of intrinsic motivation to undertake by extrinsic motivation.

$\hat{F}^{I A}=C-\left[E\left(\theta / \sigma^{*}(F), F\right) U\right] ; \hat{F}^{I S}=C-[\theta U]$. We have $\hat{F}^{I A}>\hat{F}^{I S}$.

If one was in symmetrical information, the potential creator goes on the act when $F>\hat{F}^{I S}$. In asymmetrical information, he passes to the act if $F>\hat{F}^{I A}$. As $\hat{F}^{I A}>\hat{F}^{I S}$, the public financing interval $\left[\hat{F}^{I S}, \hat{F}^{I A}\right]$ includes all public incentives for which the potential entrepreneur no longer has an incentive to create the business in asymmetrical information whereas, in symmetrical information, he would have been encouraged to do it. Over this interval, the eviction of the intrinsic motivation to undertake by extrinsic motivation is counterproductive since the entrepreneurial supply falls. 